\title{
TEORI-TEORI REALITAS SOSIAL DALAM KAJIAN MUSIK
}

\author{
A.M. Susilo Pradoko \\ Fakultas Bahasa dan Seni UNY
}

\begin{abstract}
In social research, the serious criticism that positivism is unfit to elaborate the reality of social construction emerges. The reality of social construction cannot be seen simply as science, but more contextual related to the culture in the society. Some theories to interpret the social reality are the sociology of knowledge, hermeneutics, and cultural relativism. Music is a part of culture. People, therefore, can apply those theories to interpret, elaborate, and search for the meanings of the value of the music as well as the musical phenomenon.
\end{abstract}

Key 'words: The sociology of knowledge, hermeneutics, cultural relativism, musical value, musical phenomenon

\section{A. Pendahuluan}

Dalam dunia penelitian sosial muncul perdebatan dalam mendekati realitas sosial. Satu sisi penelitian sosial serta penafsirannya didekati dengan ilmu eksak Tradisi dalam ilmu alam yang kuat dapat mengkuantifikasikan data, mencapai perumusan dan menafsirkan kenyataan sosial dalam masyarakat tokoh dalam hal ini antara lain adalah Auguste Comte. Aliran ini sering disebut Positivisme. Di sisi lain muncul teori bahwa kenyataan sosial itu sangat kompleks, menafsirkan kenyataan sosial harus melihat segala aspek kontekstual yang melekat dalam lingkungan masyarakat yang diteliti maka masyarakat tidak bisa dianalogkan sebagai benda dan dibendakan, tokohnya dalam hal ini antara lain adalah Karl Mannheim.

Dalam tulisan ini akan lebih melihat pada pandangan kedua yaitu tentang teori-teori sosial khususnya tentang teori-teori menfasirkan makna kenyataan sosial dengan menekankan pada kaitan kontekstual historis, kejadian serta lingkup masyarakat yang diteliti. Selanjutnya pemahaman akan teori-teori sosial tadi diterapkan dalam melihat paradigma dalam memaknai, menafsirkan serta mengkaji musik. 


\section{B. Pemikiran tentang Penafsiran Realitas Sosial}

\section{Sosiologi Pengetahuan}

Sosiologi pengetahuan dicipta oleh Max Scheler pada dasawarsa 1920-an di Jerman. Sosiologi pengetahuan menekuni hubungan antara pemikiran manusia dan konteks sosial dimana pemikiran itu timbul (Berger, 1966: 5) Selanjutnya tokoh sosiologi pengetahuan yang berikut adalah Karl Mannheim (1893-1947). Prinsip dasar yang pertama deari sosiologi pengetahuan karl Mannheim adalah bahwa tidak ada cara berfikir yang dapat dipahami jika asal-usul sosialnya belum diklarifikasikan. Ide-ide harus dipahami dalam hubungannya dengan masyarakat yang memproduk dan menyatakannya dalam kehidupan yang mereka mainkan (Baum, 1977: 8)

Sosiologi pengetahuan mempelajari kenyataan sosial berdasarkan pandangan bahwa kenyataan merupakan suatu kualitas yang terdapat dalam fenomen-fenomen yang kita akui sebagai memiliki keberadaan yang tidak tergantung pada kita sendiri. Sementara itu fenomen-fenomen itu nyata dan mermiliki karakteristik yang spesifik.

Pengetahuan masyarakat berbeda antar satu dengan yang lain karena memiliki karakteristik yang spesifik serta histork yang membentuknya. Sedangkan pengetahuan yang dimengerti, ide-ide dan ideologinya benar-benar riil adanya. Tugas dari sosiologi pengetahuan adalah mengungkap apa yang dianggap sebagai pengetahuan dalam masyarakat dan bagaimana pengetahuan itu dikembangkan, dialihkan, dan dipelihara dalam berbagai situasi sosial dalam masyarakat tersebut.

\section{Hermeneutik}

Hermeneutika berasal dari kata kerja Yunani hermeneuo yang berarti mengungkapkan pikiran-pikiran seseorang dalam kata-kata. Ilmu hermeneutik ini dalam sejahnya sering dipakai untuk penelitian teks-teks kuno khususnya teksteks kitab suci. Hermeneutik dipakai untuk menafsirkan, memahami dan memaknai isi-teks-teks kitab suci dan teks-teks kuno.

Dalam ilmu sosial yang dianggap teks adalah kejadian-kejadian fenomena kultural. Dalam mencapai pemahaman itu maka harus meletakkan teks pada konteksnya. Ada jaringan makna antara "teks sosial" dengan konteknya. Hardiman melukiskan cakrawala jaringan pemahaman sebagai berikut:

"Kita mengetahui suatu benda dalam kaitannya dengan benda-benda lainnya yang merupakan latar belakang dari benda-benda itu. Sebatang pensil dipahami dalam konteknya dengan benda-benda lain disekitarnya misalnya, buku, mistar,

Imaji, Vol.2, No.1, Februari 2004 : 53 - 62 
pena. Semua itu dilatarbelakangi oleh meja. Meja berada dalam konteks yang lebih luas lago yaitu dalam kaitannya dengan kursi, almari. Semua itu benda dalam konteks kamar. Rumah dalam konteks kampung, begitu seterusnya. Kalau cakrawala diperluas terus kita akan sampai pada suatu batas akhir, suatu cakrawala total yang disebut dunia. ..... Dengan kata lain manusia memahami kenyataannya sebagai suatu dunia. Perbedaan sudut pemahaman menghasilkan cakrawala yang berbeda, dan cakrawala yang berbeda menghasilkan dunia yang berbeda" (Hardiman, 2003:45)

\section{Relativisme Budaya}

Sejalan dengan pemikiran ini maka para ahli socio-antropologi mengungkapkan bahwa dalam masyarakat di dunia ini yang perlu disadari adanya relativitas kebudayaan. Dalam buku Buku: The Social Experience diungkapkan sebagai berikut:

"We cannot grasp the behavior of other peoples if we interpret what they say and do in the light of our values, beliefs, and motives. Instead we need to examine their behavior as insider, seing it within the framework of their values, beliefs, and motives. This aproach,termed cultural relativism, suspends judgement and views the behavior of people from the perspective of their own culture" (Zanden, 1988: 69). berikut:

Sedangkan dalam situs tentang relativisme budaya terungkap sebagai

"Cultural Relativism: Truth Is Relative. Cultural relativism is the position that all points of view are equally valid and that all truth is relative to the individual and his or her environment. All ethical, religious, political and aesthetic beliefs are truths that are relative to the cultural identity of the individual. Relativism can include moral relativism (ethics are relative to the social construct), situational relativism (right and wrong depend on the particular situation), and cognitive relativism (truth is relative and has no objective standard). " (http:// www culturalrelativism.com)

Relativisme budaya berpandangan bahwa semua kebenaran budaya itu relative tergantung pada sisi mana orang itu memandang. Kebenaran itu harus dilihat dari sisi historis dialektik dimana orang, masyarakat itu hidup dalam lingkungan budayanya dengan segala pranata-pranata, intitusi dan way of life jalan pikiran masyarakat tersebut. Dalam menilai kebenaran tidak bisa dengan model pranata-pranata, nilai-nilai dan kepercayaan kita. Apa yang dianggap sebagai baik, 
benar, bernilai tidak demikian bagi kelompok lingkungan masyarakat lain. Hal inilah yang harus kita perhatikan dalam memaknai, menilai dan menafsirkan kebudayaan lain.

\section{Paradigma Emik.}

Kata emik berasal dari kata fonemik ilmu tentang bunyi yang membedakan makna. Suara yang dihasilkan manusia dapat bermacam-mavam dan berjutaan jumlahnya. Tetapi dalam penggunaannya hanya sedikit bunyi yang bermakna. Fonemik menekankan pendalaman tentang bunyi-bunyi bahasa yang mengandung makna bagi manusia.

Definisi pandangan emik menurut Lett (1987:130) adalah sebagai berikut:

"Emic construct are account, descriptions, and analysis expressed in terms of the conceptual, schemes and categories regarded as meaningful and appropriate by the native members of the culture whose beliefs and behaviors are being studied".

Dalam pendekatan emik peneliti tidak membuat ukuran-ukuran maupun kriteria-kriteria sendiri dalam mengamati fenomena kebudayaan. Pendekatan ini berusaha menangkap bahasa maupun kebudayaan masyarakat itu dengan ukuran dan kriteria pemilik bahasa ataupun kebudayaan masyarakat yang diteliti. Sudut pandang emik adalah sudut pandang insider. Ketika ditemukan data yang relevan, data itu akan selalu dihubungkan dengan konteks hubungan dengan jaringan peristiwa-peristiwa yang lain dalam kebudayaan yang diteliti. Arti data yang ditemukan, sesuai dengan arti pemilik kebudayaan itu sendiri. Tujuan pendekatan emik adalah mencari makna sesuai dengan pendefinisian masyarakat pemilik kebudayaan itu. (Pradoko, 1996: 172)

\section{Penerapan Berbagai Teori Sosial dalam Kajian Musik.}

Dalam musik ada aliran referensialisme menyatakan bahwa nilai karya musik itu diluar karya musik itu sendiri. Nilai karya musik sangat melakat dengan konteks kultur dimana musik itu hidup, dihidupi dan berada dalam masyarakatnya.

Reimer menyatakan sebagai berikut: .... "According to this view, the meaning and value of a work of art exist outside the work it self. To find an art work meaning, you must go to the ideas, emotions, attitudes, events, which the work refer you in the world outside the art work. " (Reimer, 1989: 17)

Fungsi karya seni bagi aliran ini adalah adalah untuk mengingatkan tentang, menceritakan tentang, atau membantu untuk mengerti atau berpengalaman sesuatu

Imaji,Vol.2, No.1, Februari $2004: 53-62$ 
ekstra artistik yaitu sesuatu yang di luar benda kreativ dan kualitas artistik yang membuat benda itu dikreasikan. Dalam musik suara sebagai penghantar utuk mengingatkan sesuatu atau memberikan jejak atau tanda sesuatu di luar musik. Tingkat kesuksesan musik adalah menghantar ke pengalaman non musik. Tingkat pengalaman non musikal sebegiu penting dan bernilai sejauh itu pula musik itu sendiri penting dan bernilai.

Musik di dunia ini sebenarnya sebegitu banyak jenis dan variannya hingga kita tidak mampu menghitung apalagi mengapresiasi dan bahkan memainkannya. Kita sering hanya mampu mengapresiasi beberapa jenis musik saja terutama musikmusik yang dekat dengan lingkungan dan kehidupan kita atau jenis musik yang kita pelajari.

Ketika penulis melakukan penelitian gamelan sekaten seseorang pengunjung dari jakarta mengatakan sebagai berikut: " Wah ini musik orang sabar nih .......! ? Orang Yogya ni sabar-sabar, kalau saya udah nggak sabar nonton begini. Yook, saya udah mulai nggak tahan. (Pradoko, 1995:94). Sementara masyarakat pendukung gamelan sekaten begitu tampak antusias, merasakan keindahanya, nyaman, tenram, damai dan senang dapat berdekatan dengan gamelan sekaten serta menikmati alunan bunyinya.

Adanya relativitas dalam mengkaji musik maka paradigma mendifinisikan arti musik juga berubah maka dalam musik tidak harus meliputi tiga unsur utama yaitu ritme, harmoni dan melodi sebagai satu kesatuan. Bisa terjadi hanya ada satu unsur saja, dua unsur saja, ketiga unsur atau bahkan ada kategori lain.

Dalam kategori musik etnik ada misalnya musik gamelan, musik gamelan ini ada unsur melodinya, iramanya namun unsur kategori harmoni dalam konteks barat tidak ada, yang ada adalah permainan nada-nada yang saling susul menyusul. Dalam permainan nada-nada yang saling susul-menyusul tersebut ada 2 nada yang kadang cocok yang disebut dengan loro manis namun tidak ditemukan model harmoni 3 suara.

Musik Gejog Lesung yang begitu digemari oleh masyarakatnya ternyata juga tidak memiliki harmoni. Dalam permainan ini hanya ada unsur irama dan melodi. Demikian pula dengan Ndolalak dan Jatilan.

Suatu ketika Slamet Abdul Syukur, seorang tokoh musik kontemporer bersama murid-muridnyanya membuat komposisi dengan memukul-mukul bebatuan stalagmit dan stalagtit yang berada dalam gua dan ini juga dikatakan musik.

Irwansyah Harahap, seorang dosen USU dalam suatu semlok radio musik etnik menceritakan sebagai berikut: “ Ada seorang tokoh musik barat, sedang 
memasang peralatan-peralatan rekaman di tepi pantai. Penduduk setempat yang diajak kemudian bertanya: " Katanya mau merekam musik, mana musiknya kok tidak ada ? dijawab: " Musiknya ya ini, coba dengarkan suara-suara gemuruhnya ombak , angin yang bertiup dan gemerciknya lemparan air " Ini adalah musik alam, musik dari Tuhan ".

Aliran semacam ini bisa juga dikategorikan sebagai aliran musik Congcrete yang menamakan diri Musik Congcrete para aliran ini menyatakan bahwa setiap benda, materi yang berasal dari lingkungan kita bisa menjadi materi musik. Menurut (Mack, 1995:53) pengertian musik Congcrete ditlukiskan sebagai berikut: "Yang dimaksud oleh pencipta nama ini adalah bahwa bukan suatu alat musik menjadi sumber bunyi, melainkan setiap bunyi yang berada di lingkungan kita bisa menjadi materi dasar dalam arti object trouve (obyek temuan).

Lain halnya dengan musik elektronis, musik elektronis justru menghindari hal-hal yang bersifat kongkret. Mack $(1975,58)$ menyatakan antara lain sebagai berikut: "1.Musik elektronik itu dengan sengaja ingin menghindari segala asosiasi kongkret dan ilustratif.2.Secara historis pengertian asli musik elektronis hanya berlaku dari awal sampai dengan akhir 50-an, sedangkan selanjutnya pengertian menjadi luas, baik dari segi teknologi, maupun dilihat dari segi estetika komposisi, peralatan dan genrenya. 3. Sebagai istilah dari suatu gaya, pengertian musik elektronis mengarah pada peralatan musik ...."

Adanya relativitas dalam mengkaji musik maka paradigma mendifinisikan arti musik juga berubah. Pandangan (Jamalus,19988:1) tentang definisi musik adalah suatu hasil karya seni bunyi dalam bentuk lagu atau komposisi musik, yang mengungkapkan pikiran dan perasaan penciptaannya melalui unsur-unsur musik yaitu irama, melodi, harmoni, bentuk struktur lagu dan ekspresi sebagai satu kesatuan tidak tepat lagi.

Dalam berkarya dan berekspresi musik tidak harus meliputi tiga unsur utama yaitu irama, harmoni dan melodi sebagai satu kesatuan. Bisa terjadi hanya ada satu unsur saja, dua unsur saja, ketiga unsur atau bahkan ada kategori lain. Dalam musik budaya tertentu tidak harus ada harmoni juga diungkapkan Suharjo Parto sebagai berikut:

:" .... Sebagai musik tradisi timur, musik dalam drama No menurut Akira Tamba memiliki ciri: 1) Ketiadaan ide tentang nada yang pasti, 2)Tiadanya harmoni, 3)Tiadanya ritme yang teratur, 4)Teknik vokal yang kha, dan 5) sistem komposisi yang menggunakan sel-sel melodi yang masing-masingnya terdiri dari beberapa nadna. Sel-sel ini mengingatkan kita pada nyanyian dalam gendre Kentrung dalam tradisi rakyat jawa di Rembang dan sekitarnya." (Parto, 1989: 47)

Imaji, Vol.2, No.1, Februari 2004 : 53 - 62 
Ada unsur relativitas dalam menilai dan mengapresiai musik, berkaitan dengan itu (Harahap, 2000: 3) menuliskan sebagai berikut: Musik hanya bisa dipahami berdasarkan konteks kultural dimana musik itu berada. Musik tidak dapat diberi nilai "baik atau buruk", karena masing-masing masyarakat memiliki kaidah estetis maupun etis tersendiri terhadap musiknya. ....

Penilaian dalam konteks musik-musik yang ada di dunia (World Music) harus memandang adanya unsur konteks budaya, sosial dan historis dimana musik itu tumbuh dan berkembang serta mendapat pendukung dari masyarakatnya. Dalam tulisan ini akan menguraikan tentang relativitas penilaian dalam musik serta upayaupaya untuk mengkaji dan mendalami musik konteks budaya lain agar tidak terjadi salah penafsiran maupun penilaian terhadap musik budaya lain.

Setiap jenis musik memiliki historis terbentuknya musik tersebut, ssituasi dalam masyarakatnya dan dukungan masyarakatnya. Pola pikir dan budaya masyarakatnya akan membentuk dan mengekspresikan pula musik-musik yang sesuai dengan situasi masyarakat dalam konteks sosio budayanya.

Susanne Langer menyatakan bahwa musik merupakan simbol-simbol yang dapat digunakan sebagai komunikasi untuk mengekspresikan keingininan kehidupan manusia : “ .... Music is significant form, and its significance is that of symbol, a hyghly articulated, sensous object, which by virtue of its dinamic structure can express the forms of vital experience which langguage is pecurliarly un fit to convey feeling, life, motion and emotion constitute its import " (Langer, 1957: 32)

Sebagai bahasa yang diekspresikan melalui bunyi maka wujudnya diekspresikan dalam lambang-lambang. Lambang-lambang hasil ciptaan musik melalui vokal dan intrumennya sering tidak dinyatakan dengan sangat jelas ( vulgar, wadag) namun diciptakan tersamar sehingga menimbulkan daya imaginasi dan menimbulkan kekayaan keindahan. Banyak sekali lagu-lagu kritikan sosial masyarakat yang diekspresikan secara tersamar, bila dinyatakan jelas bisa terjadi pencita dan komunitasnya akan ditangkap oleh pihak yang dikritik. Selain kritik sosial juga lagu /musik yang mengekspresikan cinta, kasih sayang, kesedihan, perjuangan, pengorbanan tidak diekspresikan secara wadag. Untuk mengkaji, manafsirkan, mengungkap makna, mendalami rasa keindahannya maka kita perlu meletakan pada posisi karya tersebut dibuat, melihat secara kontekstual sesuai dengan pengetahuan masyarakat pembuat budaya tersebut. 


\section{E. Penutup}

Dalam penelitian sosial muncul berbagai teori post positivisme dimana penelitian sosial-masyarakat tidak bisa dikuantifikasikan, realitas sosial tidak bisa di-eksak-an. Kompleksitas manusia dalam budaya masyarakatnya tidak dapat dianggap benda/ dibendakan mereka merupakan subyek-subyek semua. Maka untuk memahami kenyataan yang ada muncul berbagai teori dan metode dalam mengkaji masyarakat di luar paradigma positivime.

Berbagai paradigma dalam melihat realitas sosial itu adalah: 1. Sosiologi pengetahuan yang muncul dari para ahli sosiologi. Pengetahuan yang didalamnya terdapat ide-ide, ideologi adalah berbeda dari masyarakat yang satu dengan masyarakat yang lain. 2. Ilmu Hermeunitik adalah ilmu yang berasal dari ilmu filsafat. Ilmu ini digunakan untuk mengkaji teks-teks, bahwa dalam memaknai isi teks harus dilihat berbagai konteks yang ada dibalik dan didalamnya. 3. Relativisme Budaya, ilmu ini berasal dari disiplin antropologi. Nilai-nilai kebudayaan yang satu akan berbeda dengan kebudayaan yang lain. Kita tidak bisa menilai bahwa kebudayaan lain itu buruk semata-mata hanya dengan "kacamata" budaya kita. 4 . Dalam antropologi ada paradigma Emik yaitu menilai budaya suatu masyarakat dengan ukuran masyrakat itu sendiri.

Berbagai paradigma ilmu sosial yang saya sebut post positivisme tadi sangat tepat didukan dalam pengkajian musik. Dalam meneliti, mamaknai, dan menilai musik agar tidak menimbulkan prasangka dan penafsiran yang keliru maka dapat memanfaatkan teori-teori ilmu-ilmu sosial tersebut. Penilaian, penafsiran dan pemaknaan dengan melihat secara kontekstual sosiologi gagasannya, idenya, historinya. Selanjutnya melihat secara kontekstual teks-teks yang ada yang saling terkait dan melihat secara horisontal dan vertikal menelusuri kejadian-kejadian peristiwanya. Akhirnya melihat dari aspek ukuran sisi budaya dimana musik itu ada, tercipta, hidup dan dihidupi oleh masyarakat pendukungnya.

\section{DAFTAR PUSTAKA}

Baum, Gregory.1997. Agama dalam Bayang-banyang Relativisme. Terjemahan: Ahmad Murtajib C. dkk, cetakan pertama. Yogyakarta: Tiara Wacana.

Berger, Arthur Asa. 2000. Tanda-tanda dalam Kebudayaan Kontemporer Terjemahan M.Dwi Marianto. Yogyakarta: Tiara Wacana.

Berger, Peter L. dan Thomas Luckmann. 1990. Tafsir Sosial atas Kenyataan. Trejemahan Hasan Basari. Jakarta: LP3ES

Imaji, Vol.2, No.1, Februari 2004 : 53 - 62 
Bertens K.. 1998. Ringkasan Sejarah Filsafat. Yogyakarta: Kanisius.

Charon, Joel M..1992. Sosiology A Conceptual Approach . London: Simon \&Schuster, Inc.

Hardiman, Budi F. 2003. Melampaui Positivisme dan Modernitas Yogyakarta: penerbit Kanisius

Harahap, Irwansyah. 2000. Etnomusikologi . Diktat Pelatihan Produksi Siaran Musik Etnik di Radio.

Kennick,W.E. 1979. Art and Philosophy. New York: Martin's Pree.Inc.

Langer, Susanne K.. 1957.Problems of Art: ten philosophical lectures. New York: Scribner's.

Mack, Dieter. 1995. Sejarah Musik IV. Yogyakarta: Pusat Musik Liturgi.

Parto, F.X.Suhardjo.1989. "Musik, Etnisitas dan Abad XX” Dalam: Musik Seni Barat Yogyakarta: Pustaka Pelajar.

Pradoko, Susilo. 1995. Fungsi serta Makna Simbolik Gamelan Sekaten dalam Upacara Garebeg di Yogyakarta . Thesis, Universitas Indonesia.

1996."Paradigma Emik dan Etik dalam Penelitian Etnomusikologi". Diksi. Yogyakarta: FBS IKIP Yogyakarta, halaman 170 $-177$

Reimer, Bennett. 1989. A.Philosophy of Music Education. New Jersey: PrenticeHall.Inc.

Solomon, Robert.C. dan Kathleen M.H.. 2002. Sejarah Filsafat. Yogyakarta: BentangBudaya.

Zanden, James W.V. 1988. The Social Experience. New York: Random House Inc. 